\title{
ИЗУЧЕНИЕ СВЯЗИ ВРОЖДЕННОЙ И ПРИОБРЕТЕННОЙ ИНВАЛИДНОСТИ И ВЫБОРА КОПИНГ-СТРАТЕГИЙ 14
}

Севастьянова У.Ю. (Костромской государственный университет, Кострома, Россия) ulyanakostroma@mail.ru 乙tipluјшgर्üध uर्रu. '01.08.2019

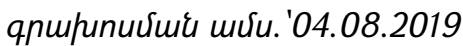

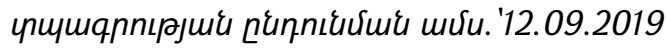

В статье анализируются копинг-стратегии поведения людей с приобретенной и врожденной инвалидностью. Исследование феноменологии совладающего поведения у взрослых людей с врождённым и приобретённым инвалидизирующим заболеванием показало специфику выбора копинг-стратегий, обусловленных восприятием нарушения, временем течения нарушения, а также личностными (диспозиционными) и социальными факторами. Мы можем отметить, что близкие отношения (социальный фактор) может быть ресурсом совладания с трудными жизненными ситуациями, в том числе и с заболеванием. Выявлены значимые различия в копинг-стратегиях у людей с врожденными и приобретенными заболеваниями. Основные различия показателей у людей с приобретенной и врожденной инвалидностью проявляются в сфере переосмысления ситуации и продуктивного ее решения.

Ключевые слова: копинг-стратегии, диадический копинг, врождённое нарушение, приобретенное нарушение, инвалидность.

Феномен совладающего поведения как индивидуального, так и группового субъекта остается объектом исследования психологии на протяжении многих лет. В настоящее время основное внимание сосредоточено на проблематике диадического (парного, семейного) совладания. Оно рассматривается как важнейший ресурс стабильности и жизнестойкости семейной системы. Всегда рассматривается как системное событие, при этом имеет тесные связи с психологическим благополучием партнеров и зависит от степени их здоровья (Дж. Койн, Д. Смит). Совладающее поведение позволяет субъекту справиться со стрессом или трудной жизненной ситуацией с помощью осознанных действий, адекватных личностным особенностям и ситуации (Крюкова Т.Л., 2004, 2008).

За последнее десятилетие на государственном уровне изменилось отношения к инвалидам, однако, лица, имеющие нарушения в состоянии здоровья, находятся в условиях, кардинально отличающихся от жизни людей с типичным развитием. Им сложнее передвигаться по городу, вступать в социальные взаимодействия,

${ }^{14}$ Исследование выполнено при финансовой поддержке РФФИ (проект № 18-313-00243) 
трудоустроиться. Сужение круга социальных контактов, приводит к ощущению неопределенности будущего у человека (Е.В. Морозова, 2008).

Инвалидность может влиять на развитие патологических процессов личности, и, таким обозом, вызывает у человека ряд психологических новообразований: замкнутость, отсутствие уверенности в себе, заниженную самооценку, агрессивность. Данные особенности человека негативно сказываются на создание близких отношений с партнером, социализации в обществе. Приобретенное нарушение в зрелом возрасте является трудной жизненной ситуацией для человека, с которой порой он не может справиться. Врожденное же нарушение является фактором формирующейся и развивающейся личности. Таким образом, совладающее поведение людей зависит от времени появления нарушенного развития.

Между тем, в отечественной литературе практически нет исследований, посвященной данной тематике. Мы выделили некоторые направления современных исследований в области совладающего поведения лиц с приобретенными и врожденными нарушениями.

Одним из них является изучение индивидуального копинга категории лиц с ограниченными возможностями здоровья (врожденные нарушения). Рассматривая, проблему совладающего поведения лиц с инвалидностью, большое внимание уделяется категории с сенсорными нарушениями (в частности патологии зрения). К данным исследованиям можно отнести работы Т.Н. Кондюхова (2004), Н.П. Терентеевой (2004), Е.А. Ивановой (2010), Е.В. Тюнеевой (2012), М.С. Поповой, О.А. Екимчик (2016), А.А. Реуновой (2016); Е.В. Куфтяк, А.П. Лебедева, А.А. Реуновой, У.Ю. Севастьяновой (2017) [3]. Также есть немногочисленные сравнительные исследования особенностей копинг-стратегий с врожденным и преобретиенным нарушением опорно-двигательного аппарата (Романова Е. В., Толкачева О. Н., 2015; Ковалева Е.Л., 2016) [2; 4].

В настоящее время зарубежная психология имеет достаточное количество исследований в области изучения срессоустойчивости, рсурсов личности людей с врожденной и приобретенной патологией. Так, например, Ehlert U., 2002; Kühl K. выявили, что ситуация болезни, инвалидности одного из партнеров является стрессовым событием для пары. Заболевание оказывает значительное влияние на психологическое здоровье пациентов и косвенно влияет на их партнера (Ehlert U., 2002; Kühl К.) [6; 7]. Уровень стресса у лиц с приобретенной инвалидностью изучали Belkin A., Albright K., Swigris J. (2013), Revenson T. at all, 2005; Ashmore J., Emery C., Hauck E., Maclntyre N., 2005. В исследованиях были получены данные о высокой потребности респондентов в эмоциональной поддержке [5; 8; 9].

Таким образом, данная научная проблема базируется на актуальной и бесспорной необходимости изучения и систематизации знаний по проблематике совладающего поведения людей с врожденной и приобретенной инвалидностью. 
Целью настоящего исследования являлось выявление особенностей копингстратегий лиц с врожденным и приобретенным нарушением (инвалидностью).

Применяемые методы исследования: Опросник способов совладания ОСС (S. Folkman, R. Lazarus (1988), адаптация Т.Л. Крюковой и др., 2004); Опросник диадического совладания Г. Боденманна (Dyadic Coping Inventory - DCl, 2008) в адаптации Т.Л. Крюковой и О.А. Екимчик, 2017 [1].

Выборка включала 2 группы респонденов: 1 группа -люди, имеющие приобретенную инвалидность $(\mathrm{n}=16)$, вторая группа - люди с врожденной инвалидностью $(\mathrm{n}=30)$. В обеих группах представлены следующие нозологии: нарушение опорнодвигательного аппарата; сенсорные нарушения; инвалидизирующие соматические заболевания.

Приведем некоторые результаты исследования. Мы проанализировали данные об индивидуальном и парном совладании. Для выявления стратегий индивидуального совладания респондентов в трудной жизненной ситуации мы использовали опросник способов совладания.

В группе лиц с приобретенной инвалидностью наиболее выраженно проявляется копинг-стратегия «Положительная переоценка» ( $M=15,5 ; \mathrm{SD}=2,56)$. Следующие в порядке убывания стратегии совладания были: “Самоконтроль» $(M=14,5 ; S D=2,82)$, «Планирование решения проблемы» $(M=14,0 ; S D=3,42)$, «Поиск социальной поддержки» (M=13,37; $S D=2,77)$, «Бегство-избегание» (M=12,75; $\mathrm{SD}=3,10)$, «Конфронтация» (M=10,12; $\mathrm{SD}=1,12)$, «Дистанцирование» $(M=9,87$; $\mathrm{SD}=2,79)$ и «Принятие ответственности» $(\mathrm{M}=8,12 ; \mathrm{SD}=1,81)$.

Стратегия положительной переоценки, которая характерна для группы с приобретенной инвалидностью, предполагает попытки преодоления негативных переживаний в связи с заболеванием за счет ее положительного переосмысления жизни, рассмотрения ее как стимула для начала чего-то, переоценке проблемной ситуации.

В группе лиц с врожденной инвалидностью самой выраженной является стратегия «Самоконтроль» ( $M=12,1 ; \quad \mathrm{SD}=2,73)$. Далее в порядке убывания выраженности следуют: «Планирование решения проблемы» $(M=11,8 ; \mathrm{SD}=2,56)$, «Положительная переоценка» ( $M=11,7 ; \mathrm{SD}=3,85)$, «Бегство-избегание» ( $M=11,33$; $\mathrm{SD}=4,59)$, «Поиск социальной поддержки» $(M=11,3 ; \mathrm{SD}=3,53)$, «Дистанцирование» $(M=9,16 ; \quad S D=3,57), \quad$ «Конфрронтация» $(M=8,43 ; \quad S D=2,45)$ и «Принятие ответственности» $(M=6,83 ; \mathrm{SD}=2,64)$.

Стратегия самоконтроля, которая преобладает у данной группы испытуемых, предполагает попытки преодоления негативных переживаний в связи с проблемой за счет целенаправленного подавления и сдерживания эмоций, минимизации их влияния на оценку ситуации и выбор стратегии поведения, высокий контроль поведения, стремление к самообладанию. 
Человек с врожденным нарушением часто скрывает от окружающих свои переживания, боясь осуждения или жалости со стороны общества. Поэтому он склонен контролировать свои эмоции и поведение.

Также были выявлены статистически значимые различия в выраженности копинг-стратегий у инвалидов с врожденными и приобретенными заболеваниями. Сравнение результатов по критерию Манна-Уитни, выявило значимые различия по параметру «Положительная переоценка» $(U=48,0 ; p=0,008)$, «Планирование решения проблемы» $(U=61,0 ; p=0,03)$ между группами. Данные стратегии выражены у группы с приобретенной инвалидностью. В ситуации приобретенной инвалидности, сопровождающейся высоким стрессом и трудно поддающейся контролю, более эфффективными оказываются стратегии, направленные на переосмысление ситуации и преодоления проблемы за счет целенаправленного анализа ситуации и возможных вариантов поведения, выработки стратегии разрешения проблемы, планирования собственных действий с учетом объективных условий. Стратегия рассматривается большинством исследователей как адаптивная в ситуации появившегося серьезного заболевания.

Таким образом, основные различия показателей у людей с приобретенной и врожденной инвалидностью проявляются в сфере переосмысления ситуации и продуктивного ее решения.

Анализируя данные по методике диадического совладания испытуемых, мы можем выделить следующие положения. Наиболее высокие показатели в двух группах обнаружены по шкале «Поддерживающий диадический копинг». Диадический копинг людей с приобретенной инвалидностью представлен доминированием стратегии поддерживающего копинга субъекта ( $M=21,0 ; \mathrm{SD}=2,26)$ и общего диадического копинга $(M=17,5 ; S D=4,24)$. Эта же тенденция сохраняется для лиц с врожденной инвалидностью: поддерживающий $(M=17,6 ; S D=3,46)$ и общий диадический копинг $(M=17,8 ; \mathrm{SD}=3,81)$. Поддерживающий диадический копинг возникает, когда один из партнеров предоставляет проблемно-ориентированную или эмоционально-ориентированную поддержку, которая помогает другому партнеру в совладании. Респонденты поддерживают партнера в трудной ситуации, дают почувствовать ему, что понимают его, готовы помочь. Партнеры, состоящие в близких отношениях, уделяют больше внимания друг другу, пытаются решить проблему диалогом. Также у данных групп менее всего выражена шкала «Делегированный диадический копинг» (M=6,87; $\mathrm{SD}=2,41 ; \mathrm{M}=6,3 ; \mathrm{SD}=2,24)$. Делегированный диадический копинг возникает, когда один из партнеров берет на себя ответственность с целью уменьшения стресса своего партнера. Эти данные свидетельствуют о ригидности распределения функциональных обязанностей в паре.

Сравнение результатов по критерию Манна-Уитни, выявило значимое различие по одному параметру «Поддерживающий диадический копинг субъекта» 
$(U=49,0 ; p=0,01)$ между группами. Данные стратегии выражены у группы с приобретенной инвалидностью.

Таким образом, в соответствии с нашими данными о большей выраженности поддерживающего и меньшей выраженности делегированного диадического копинга у респондентов, являющихся репрезентативной группой выборки, больше распространено индивидуальное совладающее поведение при наличии поддержки партнера (чаще всего моральной).

Исследование феноменологии совладающего поведения у взрослых людей с врожденным и приобретенным инвалидизирующим заболеванием показало специфику выбора копинг-стратегий, обусловленных восприятием нарушения, временем течения нарушения, а также личностными (диспозиционными) и социальными факторами. Мы можем отметить, что близкие отношения (социальный фактор) может быть ресурсом совладания с трудными жизненными ситуациями, в том числе и с заболеванием.

Таким образом, мы видим, что для людей с врожденной и приобретенной инвалидностью характерна повышенная стрессоустойчивость, высокая подверженность социальным нормам, высокий самоконтроль, большая осмысленность и продуктивное решение проблемной ситуации.

Полученные научные данные по изучаемой проблематике являются актуальными и необходимыми для оказания консультативной и коррекционной помощи людям с врожденной и приобретенной инвалидностью.

\section{Литература}

1. Екимчик О.А., Крюкова Т.Л. Диадический копинг в российских парах: исследование психометрических качеств Опросника диадического совладания Г.Боденманна // Психологические исследования. 2017, Т. 10, № 55, С. 4. [Электронный ресурс]. - Режим доступа: URL: http://psystudy.ru (дата обращения: 22.09.2018).

2. Ковалева Е.Л. Копинг-стратегии людей с инвалидностью с разным уровнем ролевой виктимности // Электронный журнал «Клиническая и специальная психология» 2016, Том5, № 4, С. 93-102.

3. Лебедев А.П., Реунова А.А., Севастьянова У.Ю., Куфтяк Е.В. Адаптационные механизмы у детей с ограниченными возможностями здоровья // Вестник КГУ. Серия «Педагогика. Психология. Социокинетика», 2017, № 2, С. 169-173.

4. Романова Е.В., Толкачева О.Н. Сравнительное исследование копингстратегий, особенностей межличностных отношений и смысложизненных ориентаций у лиц с врожденными и приобретенными заболеваниями опорно-двигательного аппарата // Вестник Санкт-Петербургского университета, 2015, Вып.4, Сер. 12, С. 87 - 97. 
5. Belkin A., Albright K., Swigris J.J. A qualitative study of informal caregivers' perspectives on the effects of idiopathic pulmonary fibrosis // Open Resp Res, 2013, №10, P. 136 - 158

6. Ehlert U. Verhaltensmedizin [Behavioral health]. - Berlin, Germany: Springer; 2002.

7. Kühl K., Schurmann W., Rief W. Mental disorders and quality of life in COPD patients and their spouses // Chron Obstruct Pulmon Dis. 2008, №3, P. 727736.

8. Revenson T.A., Abraido-Lanza A.F., Majerovitz S.D., Jordan C. Couples coping with chronic illness: what's gender got to do with it? //Couples couping with stress: Emerging perspectives on dyadic coping / Revenson TA, Kayser D, Bodenmann G. - Washington: American Psychological Association, 2005, P. $137-256$.

9. Revenson T., Kayser K., Bodenmann G. Couples couping with stress: emerging perspectives on dyadic coping. - Washington: American Psychological Association, 2005.

\section{STUDYING THE RELATIONSHIP BETWEEN CONGENITAL AND DISABLING DISEASES AND COPING STRATEGIES}

Sevastyanova U.Y. (Kostroma State University, Kostroma, Russia)

The article analyzes the coping strategies of the behavior of people with acquired and congenital disabilities. A study of the phenomenology of coping behavior in adults with congenital and acquired disabling diseases showed the specifics of the choice of coping strategies, due to the perception of the disorder, the duration of the disorder, as well as personal (dispositional) and social factors. We can note that close relationships (social factor) can be a resource for coping with difficult life situations, including the disease. Significant differences in coping strategies in people with congenital and acquired diseases were revealed. The main differences in indicators in people with acquired and congenital disabilities are manifested in the rethinking of the situation and its productive solution.

Keywords: coping strategies, dyadic coping, congenital disorder, acquired disorder, disability. 